\title{
Analysis of Usage Behavior and Preference in Senior-Friendly Parks for the Aging Society
}

\author{
Yong Jo Jung ${ }^{1 *}$ and Su Deok Chae ${ }^{2}$ \\ ${ }^{1}$ Department of Environmental Landscape Architecture, Sangmyung University, Chungnam 31066, Korea \\ ${ }^{2}$ Department of Environmental Science and Ecological Engineering, Graduate School of Life and Environmental Science, Korea \\ University, Seoul 02841, Korea
}

\section{ABSTRACT}

The Korean society is currently showing a decrease in the child population and a rapid increase in the elderly population due to low birth rates and aging, but the current park system does not reflect the changing population structure. This study aimed to find ways to plan and promote use of senior-friendly parks for the aging society. The results are as follows. First, the elderly mostly gathered in Tapgol Park and Jongmyo Park which were accessible to subways and close to amenities and traditional markets. The elders usually gathered around buffer zones or green spaces set up to protect cultural heritages. Second, many elderly users were observed in Osolgil Silver Park and Sinteuri Park which were renovated with senior-friendly concept. These parks were recognized as places that the elderly people could visit without minding users of other generations because the elderly users were ensured by words such as 'seniors only' or 'senior-friendly'. Third, the importance of the locational conditions for the senior-friendly parks should be mentioned. A senior-friendly park must be located in an urban center to have convenient access to transportation, secure large green spaces, and make elderly users feel at ease with social connectivity when they use the amenities there. Fourth, the survey results showed that elderly people visited parks to exerciseand take a walk (track), by age, older age groups visited the park to socialize with other elders around their age. Fifth, the most desired facilities for constructing senior-friendly parks were fitness equipment, and sports facilities like a trail, track, and gateball field, and in some cases, vegetable gardens and indoor rest area to avoid wind in cold weather.

Keywords: everydayness, free time, population change, public aspect

\section{Introduction}

The United States Census Bureau forecasts that the elderly population aged 65 and over will increase from 600 million in 2015 to 1.6 billion in 2050, and its ratio will increase from $8.5 \%$ to $16.7 \%$ of the entire population (Cho and Lee, 2019). Korea first entered the aged society in 2017 when the elderly population registered as residents aged 65 and over reached 7.257288 million, taking up $14.0 \%$ of the entire population. This is just 17 years after Korea entered the aging society in 2017, which is a year earlier than forecasted by Statistics Korea. Korea's aging speed is the highest in the world, and the 17 years it has taken for Korea to enter the aged society from the aging society are a very short period of time compared to France that took 15 years, the US 73 years, Germany 40 years, and Japan 24 years. There are concerns that Korea will reach the super-aged society, in which the elderly population exceeds $20 \%$ of the entire population, much sooner than expected (2026; Oh, 2018).

This demographic change forewarns rapid transformation of the society, which is not an exception for urbanology and architecture. In other words, the elderly population that have been considered a minority and socially underprivileged

Received: September 3, 2019, Revised: September 23, 2019, Accepted: November 4, 2019

First author: Yong Jo Jung, smilejung@smu.ac.kr, (D) https://orcid.org/0000-0003-1518-2161

*Corresponding author: Yong Jo Jung, smilejung@smu.ac.kr, (D) https://orcid.org/0000-0003-1518-2161 
group in the past are now turning into key users of urban space. With this change, studies in architectural planning have been actively conducted regarding living and indoor spaces for the elderly, such as senior welfare centers, halls for senior citizens, schools or programs for the elderly, and recreation centers for the elderly. However, in terms of environmental planning, there is insufficient consideration of the elderly (Cho and Lee, 2019).

Considering that Korea has the highest poverty and suicide rates of the elderly, the tension of aging that has struck the Korean society reflects the miserable life of the elderly that faced their later years without preparations. Family disorganization in the modern society, the loss of the elderly's role in the industrial society, and the accelerated retirement induced the elders to perceive themselves as useless beings in the society, consequently facing social isolation (Chae, 2014). In this situation, the elders began to crowd into parks as if going to work every day. The elders clustering in Tapgol Park and Jongmyo Park in particular are forming their own groups and spaces, occupying the whole area of Jongno 3-ga. They are aware that the public is not showing a favorable response toward this phenomenon, but since they are not accepted by anywhere else in this society, they have no choice but to bond and create their own culture in parks where they feel less mental pressure (Chae, 2014).

Studies on the elderly use of facilities and usage conditions in areas crowded with the elderly in the city include Lee and Kim (2003), Lee (2009), and Ju (2010), which determined the characteristics of space preferred by elderly men by examining the elders that gather in Tapgol Park and investigated the park facilities that the elders want. Kim (2009) closely observed the daily life of the elders in Jongmyo Park and defined their group culture, and Song and Nam (2008) examined the elderly use of Cheongju Jungang Park and provided ways to promote use of parks for the elderly. Kang (2004) mentioned the leisure program preference of theme parks for the elderly and specific program development by conducting a survey on the elderly aged 60 and over, while Kim (2012) presented ways for the elderly to participate in park management and leisure activities through silver volunteering. This study suggested various activities of volunteer organizations autonomously run by the elderly, such as soup kitchen, autonomous cul- tural activities and medical services, and proposed establishment of welfare centers for the elderly and disabled such as kitchen gardens, snack bars and management facilities for the elderly to enjoy all kinds of culture. Lee (2012) pointed out that the leisure environment for the elderly is poor even though the child population is decreasing while the elderly population is rapidly increasing, thereby claiming that it is necessary to remodel children's parks into parks for the socially disadvantaged like the elderly or disabled that also reinforce the functions of the community. Kang and Park (2010) suggested establishing adequately sized hall and welfare center for senior citizens inside a park crowded with the elderly and running them in association with the park. They argued that it is necessary to drastically change children's parks into senior-friendly theme parks.

As examined above, topics on park activities and programs for the elderly population in the aging society have been studied in many fields. However, the Korean society is currently facing the severe issue of low birth rates and aging, with the child population decreasing and the elderly population rapidly increasing. Thus, the current park system fails to reflect the changed population structure. Accordingly, with the need for senior-friendly parks that are convenient for the elderly to use and that can improve the quality of their lives, we conducted a literature review and analyzed the usage behavior and preference of existing parks crowded with the elderly and parks that are remodeled into senior-friendly parks. We expect the findings of this study to be used in planning of parks and greens according to social changes caused by the aging society.

\section{Research Methods}

\section{Selection of parks and research scope}

This study examined and analyzed two urban parks in Seoul crowded with the elderly and two parks in Seoul renovated into senior-friendly parks. We selected Tapgol Park and Jongmyo Park in Jongno, Seoul as the parks crowded with the elderly, and Osolgil Silver Park and Sinteuri Park in Yangcheon-gu, Seoul renovated into se- 
nior-friendly parks.

The scope of research was as follows. First, we conducted a theoretical review of literature to point out the social environment faced by the elderly in the modern society as well as related issues, and examined and analyzed the tendency of the elderly in crowding into public spaces and the spaces they prefer.

Second, we examined and analyzed the park usage behavior of the elderly at Tapgol Park and Jongmyo Park, the characteristics of areas crowded with the elderly, and amenities nearby.

Third, we examined and analyzed the programs used by the elderly and their usage behavior at Osolgil Silver Park and Sinteuri Park renovated into senior-friendly parks.

Fourth, we conducted a survey and analyzed the results to determine the current state of park usage, facilities mainly used by the elderly at the park, and programs preferred by the elderly.

\section{Methods}

This study examined ways to create a neighborhood park for the elderly that can accommodate the elderly population facing problems such as poverty, social isolation and loneliness by conducting a literature review, field investigation, and a survey.

First, we reviewed related data and previous literature to analyze the current state, which include books, research papers, reports, news articles and internet materials on welfare for senior citizens and problems related to the elderly.

Second, for field investigation, we observed play behaviors of the elders for four seasons from June 1, 2016 to May 31, 2017, interviewed 80 elders aged 50s-70s, and examined and analyzed the park usage behavior of the elders.

Third, we conducted a survey on the elderly using the parks to determine the current state of park usage, facilities they mainly use, and programs they prefer. The purpose was to find out the demand of the elderly using the park and the park programs they want, thereby establishing the basic data to reflect on park design in the future.

The survey participants were the elders using Tapgol Park and Jongmyo Park in Seoul where they gather, and
Osolgil Silver Park and Sinteuri Park renovated into senior-friendly parks. The age group we have approached with interest is the elderly group rather than the new silver generation and thus we conducted the survey mostly on those aged 70s or older. However, we distributed the questionnaire to some of the $60 \mathrm{~s}$ and $50 \mathrm{~s}$ that were with the older group in the park, and thus the participants include park users aged 50 and over. 200 copies of the questionnaire were distributed, and 177 copies were analyzed excluding 23 copies with unclear responses.

We also conducted interviews to obtain individual thoughts about park usage and general information aside from the survey items. The survey was conducted for 2 days in Tapgol Park and Jongmyo Park from June 8 to 9, 2018, and also for 2 days in Osolgil Silver Park and Sinteuri Park from June 25 to 26, 2018.

The survey was comprised of 20 items on the basic data of participants, status of park usage, preferred park facilities, and what they want in creating programs and parks for the elderly. The number of survey items was minimized considering that most of the respondents are in their $70 \mathrm{~s}$ or older, making the questionnaire as simple as possible in roughly determining the preference. The results were analyzed by conducting statistical analysis (frequency analysis, cross tabulation) using SPSS.

\section{Results and Discussion}

\section{Theoretical review of literature}

In November 2013, the Asia Business Daily serialized articles on Pagoda Park (Tapgol Park), a symbolic space of the aging society, and the life of the elderly in the area to report the present conditions of the problems related to the elderly in the Korean society. The articles discussed that this area has been used exclusively by older people for a long time, functioning as a base for the elderly population that creates the identity of the elders that gathered in the area to break free from social isolation. Kim (2009) stated that the elders gathering in Jongmyo Park share emotional homogeneity in many aspects. It is a bond shared by the elders at Jongmyo Park, which is an emotional bond 
of alienation different from the homogeneity as the same generation. Regardless of the economic position, previous occupation and social status, the elders gathered in Jongmyo Park were sharing a sense of alienation, and whenever they talked about such experience, they all related to one another and criticized the present society. Lee (2012) and Kang and Park (2010) suggested turning children's parks, which are often crowded by many elders, into community parks or senior-friendly theme parks. The elders are gathering in urban parks because the neighborhood parks fail to properly meet the needs and demands of the elderly. Therefore, their studies argued that the parks planned to enable their social participation by settling into their neighborhoods will be effective in solving their problems.

For future planning of parks for the elderly, it is necessary to implement senior-friendly parks in which the elderly gathering in public places of the city can promote social participation and intergenerational exchange to create a sound and healthy senior culture, based on the fact that the elderly all have different ways of thinking, attitudes in life, and patterns of leisure activities.

\section{Park usage behavior of the elderly generation and the characteristics of areas crowded with the elderly}

\section{Tapgol Park}

We conducted interviews with the elderly using Tapgol Park about the park usage behavior and surrounding environment for four seasons from June 1, 2016 to May 31, 2017. As a result of analyzing the results, it was found that there were amenities for the elderly concentrated near Tapgol Park, creating an environment preferred by the elderly. There was a soup kitchen nearby, as well as barbershops, restaurants and street stalls selling vintage clothes and supplies for the elderly that all created a convenient environment for the elderly. The alley on the east side of Tapgol Park in particular has a vending machine that serves as a popular meeting point. The coffee is $200 \mathrm{KRW}$, and around 30 elders are usually holding paper cups of coffee and chatting nearby. There are about 20 plastic chairs around the vending machine, creating a mood like an outdoor cafe. In addition, there are Hollywood Classic, Silver Cinema and senior cafe called Polishing Memory, which offer movie screenings or coffee at a reasonable price of 2,000 KRW, thereby attracting the elders all the time. These places are frequently visited by elderly women contrary to the park that is crowded with elderly men only, which is because these places are somewhat elegant meeting spots in the area (Fig. 1).

The Tapgol Park area is very small but has an environment that is convenient for the elderly, and thus thousands of elders are visiting the area every day regardless of the season or day, staying for a long time from morning to evening. They just come here to meet people. There are parks with nice facilities and amenities near their homes as well, but they claim they are uncomfortable because of the young generation. Thus, the elders that are not welcome anywhere have no choice but to come to Tapgol Park, as they can get along with others here without constraint.

\section{Jongmyo Park}

As a result of examining and analyzing the park usage behavior of the elderly and surrounding environment for four seasons from June 1, 2016 to May 31, 2017, it was

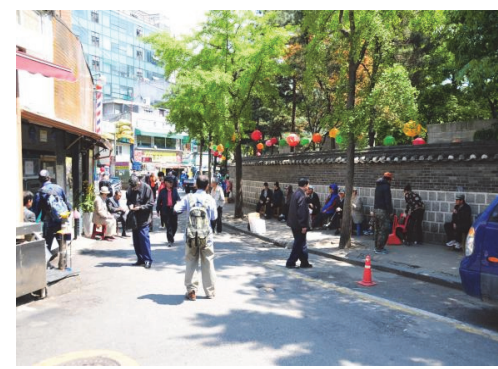

(A)

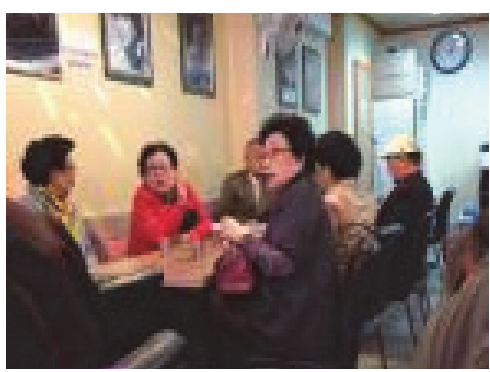

(B)

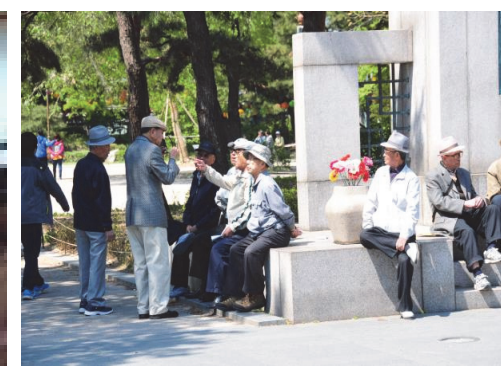

(C)

Fig. 1. Seniors in Topgol Park gathering around a coffee vending machine(A), having a conversation in a cafe(B) or near the sculpture(C). 
found that unlike the static and calm mood of Tapgol Park, Jongmyo Park was full of energy. On the day of the field investigation, there were hundreds of elderly men playing Baduk and Janggi (Korean chess) in the park, perhaps because it was a holiday. The tree guards that are also used as benches were packed full of elders, and on the streets there were games of Baduk and Janggi on aluminum insulation mats big enough for two. At Jongmyo Park, there were games set up in all spaces where people can sit, even on the streets leaving just enough space to walk by. Actually, not all elders visiting Jongmyo Park play Baduk and Janggi; there are a lot more spectators. They usually watched the players playing Janggi, and as many as a dozen spectators were crowded around each Janggi board. There were also quite a few elders sitting by themselves, and they looked relatively old and thus were spending time alone as they could not fit into the group of slightly younger elders (Fig. 2).

\section{Programs and usage behavior in parks renovated into senior-friendly parks}

\section{Osolgil Silver Park in Yangcheon-gu, Seoul}

Osolgil Silver Park is a park located in 977, Sinwol 7-dong, Yangcheon-gu (Fig. 3). Considering the fact that it was frequently used by the elderly, Yangcheon-gu installed facilities for the elderly at 'Osolgil Park' that had previously been a neighborhood park in the size of $18,047.2$ $\mathrm{m}^{2}$ (5,700 pyeong) in October 2005 and named it 'Osolgil Silver Park'. Created in August 1990, Osolgil Silver Park has a trail, badminton court, gateball field, restrooms, pavilions and a few fitness equipment and facilities. However, as more and more elders began to use the park, there was an extensive maintenance work done to the park by investing 541 million won in June 2005. Two pavilions were newly built, $550 \mathrm{~m}$ of the trail was repaired (widened from $1.2 \mathrm{~m}$ to $2 \mathrm{~m}$, urethane pavement), 4,040 trees and woody plants in six different species were planted, the gateball field was renovated, the badminton court and outdoor fitness equipment were newly built, and a new outdoor stage, stands and children's playground equipment were also installed.

In the park, a trail, woodland path, and special fitness equipment for the elderly such as arm wheels (arm exercise equipment) and rollers for stretching were installed. The trail, which is almost $600 \mathrm{~m}$ long, was paved with urethane and had the gradient reduced so that the elderly can walk more easily with less fatigue on knees and ankles. In addition, an acupressure walkway and sports facilities such as gateball field and badminton court were also installed, as well as a performance stage to support cultural activities.

One thing to note is that there were many resting build-

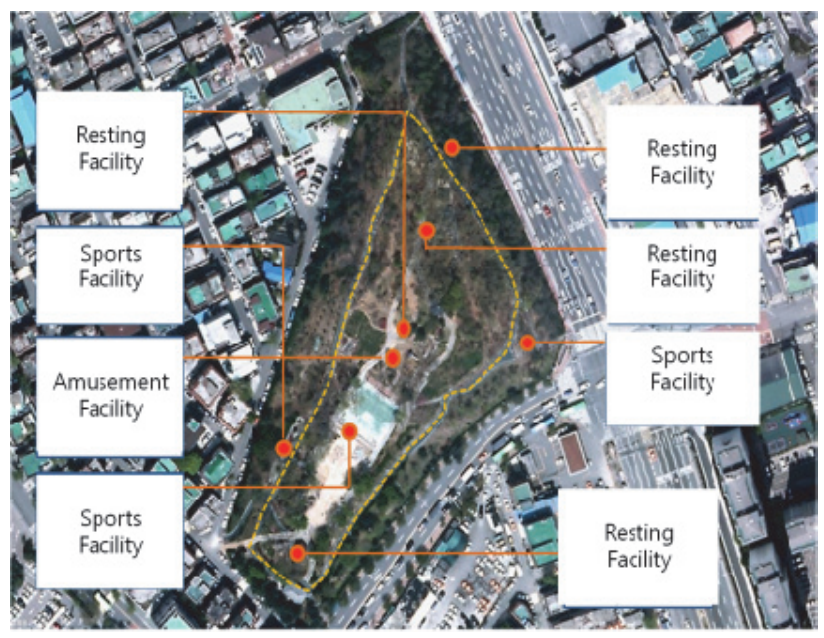

Fig. 3. Park layout map of Osolgil Silver Park.

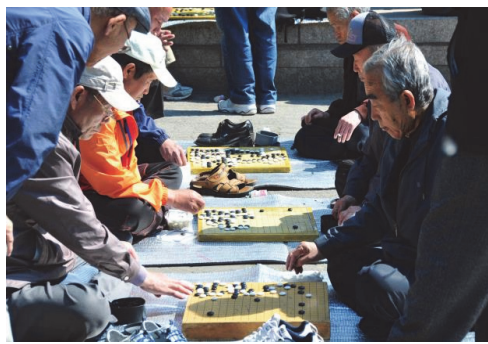

(A)

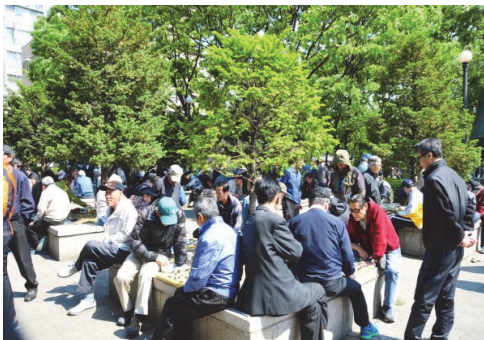

(B)

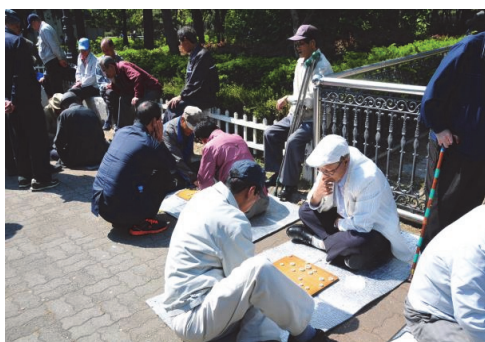

(C)

Fig. 2. Seniors in Jongmyo Park playing Baduk(A), gathering and chatting(B), and playing Janggi(C). 


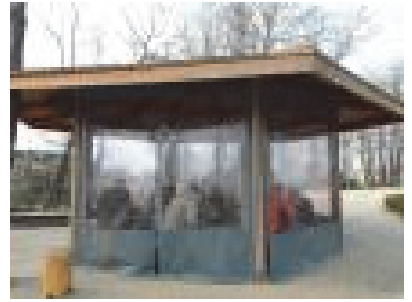

(A)

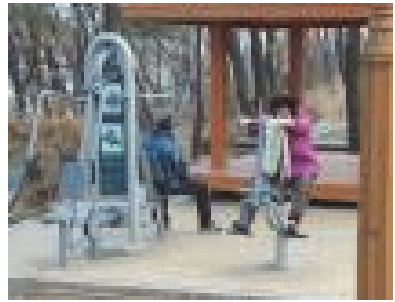

(B)

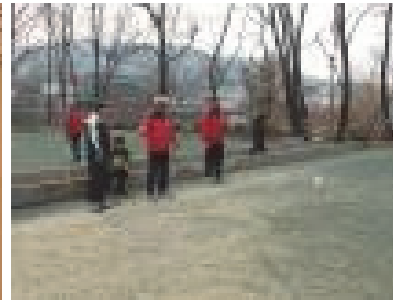

(C)

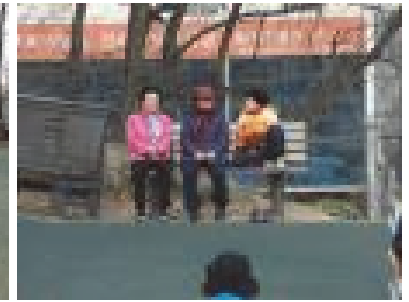

(D)

Fig. 4. Facilities in Osolgil Silver Park: a resting area(A), outdoor fitness equipments(B), gate ball field(C) and benches (D).

ings and chairs with backrests. This is contrary to the case of Tapgol Park and other children's park crowded with the elderly in which pavilions were demolished and the chairs with backrests were replaced by stools so that the elders no longer visit the area. As if designed for the purpose of rest and health of the elderly, there were five big and small pavilions for visitors to rest, along with chairs that have acupressure backrests for the elderly, and even windbreaks set up for them to use the pavilions in the winter.

There was a gateball field and badminton court in the middle of Osolgil Silver Park. Gateball does not require much strength and is easy to understand even without experience after listening to a brief explanation, and thus is a leisure activity that is extremely popular among the elderly. On the other hand, the badminton court was uncrowded, perhaps because such a strenuous exercise is too much for the elderly visitors that are mostly in their 70 s. There were also many elders using the trail or outdoor fitness equipment, and those chatting with other elders on the pavilion (Fig. 4).

\section{Sinteuri Park in Yangcheon-gu, Seoul}

Sinteuri Park is located in 310-7, Sinjeong 1-dong, Yangcheon-gu (Fig. 5) and was renovated into the present condition in 2009 after it had been serving as a neighborhood park for residents nearby. Located between apartment complexes, Sinteuri Park has Sinseo Middle School and Yangmyung Elementary School on its north, and it has been used as a nature learning park for the elementary school since 1999.

Sinteuri Park is characterized by its diverse spectacles. The most famous one is the nature learning space where wildflowers like bleeding hearts, garden plants, herbs, vines and crops are planted. There are also other unique aspects

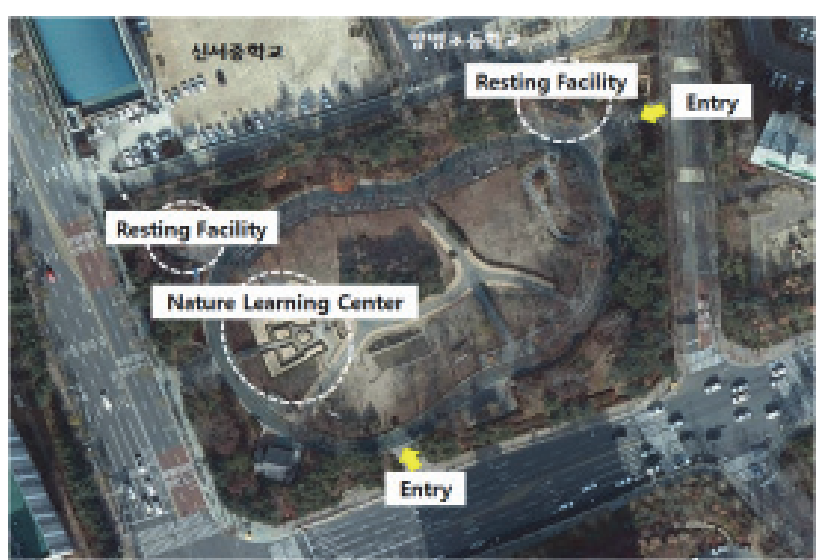

Fig. 5. Park layout map of Sinteuri Park, Seoul.

such as the rosery with over 900 types of roses, as well as props such as models of cows, lookout sheds, Korean A-frames, jars, swings and plows to make visitors feel a homey atmosphere. The most noticeable thing is that the park provided a spatial foundation that embraces the elders living in the neighborhood. The trails were all paved with urethane to improve walkability, and there were dozens of benches installed here and there. There were more low wooden benches, pavilions and pergolas than other parks. There was also sufficient fitness equipment, and windbreaks were set up to meet the needs of the elders like Osolgil Silver Park so that they can avoid the cold and play Baduk and Janggi.

Most users were jogging around the tracks or exercising on the fitness equipment, and some were using the acupressure walkway and trail. They took short breaks on the benches in between exercising. The benches were also used for the elders to sit and chat. The long pergola set up at the east entrance of the park and the pavilion in the west were spots for the elders to play Baduk, Janggi and Yut. There was a vegetable garden on the inner side of the tracks 


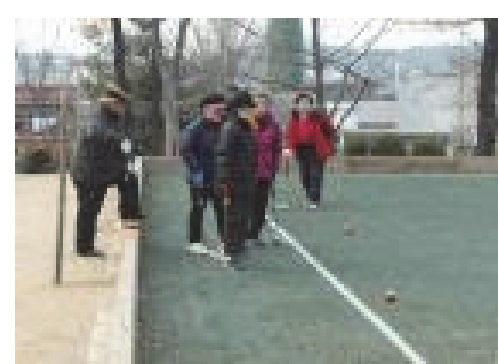

(A)

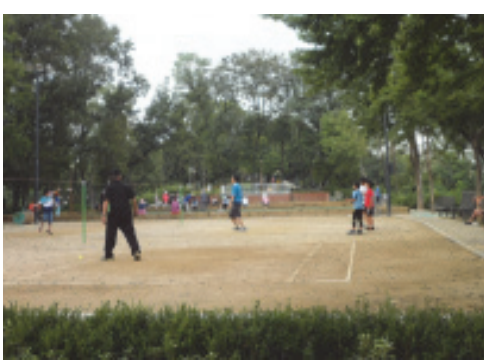

(B)

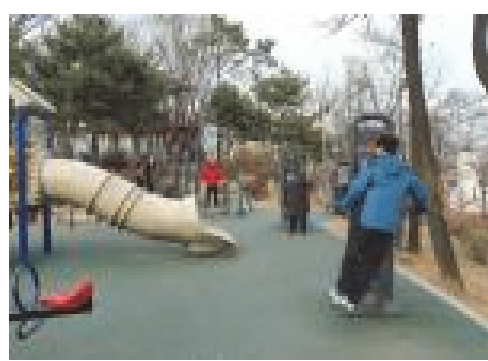

(C)

Fig. 6. Facilities in Sinteuri Silver Park: gate ball field(A), badminton courts(B), and a playground for children(C).

for the elderly to enjoy a healthy and sound leisure activity, which was used by many visitors (Fig. 6).

\section{Programs preferred by the elderly}

\section{General characteristics of respondents}

There were 92 respondents in their 70 s $(52 \%)$ and 57 in their $60 \mathrm{~s}(32 \%)$, indicating that those in their $60-70 \mathrm{~s}$ took up $84 \%$ of all respondents. Moreover, 15 were in their 80 s $(8 \%)$ and 13 were in their 50s $(7 \%)$, and thus the elders aged 60 and over took up 92.113 were men and 64 were women, with the male ratio (64\%) higher than female. One thing we could find out from the interviews conducted freely in the survey process was that some of them willingly accepted 'parks for the elderly', whereas quite a few of them refused to be seen as the elderly. Moreover, the elders visiting the parks were somewhat healthy and still had a zest for life. According to one elderly man, seniors in their 80s do not visit the park often due to physical difficulties. On the other hand, those who often come out to the park are greatly interested in health, are very sociable and get along well with other elders around the same age. Meanwhile, one thing that should not be overlooked is the fact that the age of the elderly perceived by the respondents is different from the age of the elderly in the social concept. The respondents seemed to think that those from ages 73 to 75 are 'real' elders, while the ones younger than that do not consider themselves as elders.

\section{Park usage behavior}

(1) Tapgol Park and Jongmyo Park

Approximately $90 \%$ of the respondents were living within walking distance of the park, with $68 \%$ within 10 mi- nutes and $22 \%$ within 30 minutes. However, $10 \%$ (10 respondents) needed 30-60 minutes of time to get to the park, and they usually rode a bike or took a bus to the park. None of them required more than 1 hour to get to the park.

Most of the respondents (84\%) walked to the park, 7\% rode a bike and $9 \%$ took a bus. Most of them visited the park every day (68\%), followed by 3-4 times a week (24\%), and 1-2 times a week (8\%), indicating that the elders were using the park every week.

Six percent of the respondents spent less than an hour in the park, $15 \%$ spent $1-2$ hours, $19 \%$ spent $2-4$ hours, and $50 \%$ spent more than 4 hours, taking up most of the ratio. Moreover, $10 \%$ responded that they spent all day in the park, and thus approximately $60 \%$ of the respondents spent about half a day in the park. This indicated that the elders spent a great deal of their free time in the park.

As for the time when they used the park, 5\% visited the park before 9 a.m., $11 \%$ visited at 9 a.m.-12 p.m., $9 \%$ visited at 12 p.m.-3 p.m., and 53\% visited at 3 p.m.-6p.m., indicating that approximately $62 \%$ of the elders spent their afternoon in the park. $22 \%$ of the respondents who visited the park randomly between 9 a.m. and 6 p.m. mostly visited for a brief exercise and walking, and thus may not have spent much time in the park.

Most of the elders (31\%) claimed that they visited the park to spend time with other elders, followed by $26 \%$ to use the fitness equipment or sports facilities, $24 \%$ to walk on the trail, $50 \%$ for exercise and physical training, and $19 \%$ to just rest quietly.

(2) Osolgil Silver Park and Sinteuri Park

Approximately $90 \%$ of the respondents were living within walking distance of the park, with $70 \%$ within $10 \mathrm{mi}-$ 
nutes and $20 \%$ within 30 minutes. However, $10 \%$ (8 respondents) needed 30 minutes- 1 hour of time to get to the park, and they usually rode a bike or took a bus to the park. None of them required more than 1 hour to get to the park.

Most of the respondents (80\%) walked to the park, $11 \%$ rode a bike and $9 \%$ took a bus. Here, the fact that most of them walked to the park is a result similar to other case studies, and so is the use of the bike. The fact that none of them took the subway but the bus was the only means of public transportation to the park is primarily due to the fact that the park is located far from the subway station. The elders that visited from afar even by paying the bus fare $(9 \%)$ were mostly to promote friendship with their acquaintances as previously examined.

Most of them visited the park every day (63\%), followed by 3-4 times a week (29\%), and 1-2 times a week (8\%), indicating that the elders were using the park every week.

Eight percent of the respondents spent less than an hour in the park, $20 \%$ spent $1-2$ hours, $23 \%$ spent $2-4$ hours, and $39 \%$ spent more than 4 hours, taking up most of the ratio. Moreover, $10 \%$ responded that they spent all day in the park, and thus approximately $49 \%$ of the respondents spent about half a day in the park. This indicated that the elders spent a great deal of their free time in the park. Spending all day in the park means they spend a long time at the park and nearby, but many respondents interpreted as spending time inside the park. Many of the elders spending a long time in the park enjoyed playing Baduk and Janggi, and some also played gateball. Those sitting around and chatting with other elders in the park also spent a long time, which suggests that these parks are more closely associated with the elderly lives than other parks. This is because the gu office (borough office) acknowledged the elderly's leisure behavior of killing time and thus established spaces and facilities accordingly.

As for the time when they used the park, $7 \%$ visited the park before 9 a.m., $15 \%$ visited at 9 a.m.-12 p.m., $8 \%$ visited at 12 p.m.-3 p.m., and $46 \%$ visited at 3 p.m.- 6 p.m., indicating that approximately $54 \%$ of the elders spent their afternoon in the park. $24 \%$ of the respondents who visited the park randomly between 9 a.m. and 6 p.m. mostly visited for a brief exercise and walking, and thus may not have spent much time in the park. Therefore, they have significant correlation with the $8 \%$ of elders who spent less than 1 hour and 20\% who spent $1-2$ hours (total $28 \%$ ), thereby visiting the park not for socializing but for health care.

Most of the elders $(30 \%)$ claimed that they visited the park to spend time with other elders, followed by $25 \%$ to use the fitness equipment or sports facilities, $20 \%$ to walk on the trail, $45 \%$ for exercise and physical training, and $25 \%$ to just rest quietly. By age, it was found that older groups more frequently visited the park to spend time with other elders around the same age, whereas fewer elders visited for exercise. However, light activities like taking a walk or resting still were frequently found in all respondents in their $60 \mathrm{~s}$ or over. None of the $50 \mathrm{~s}$ visited the park to meet with friends or neighbors, and $60 \%$ of them used the park to exercise or take a walk. This is a natural result considering that the 50 s are in a socially active state (Table 1).

Table 1. Characteristics of senior respondents and their park-use behavior

\begin{tabular}{|c|c|c|c|}
\hline & Classification & Frequency & Percent(\%) \\
\hline \multirow{2}{*}{ Gender } & Male & 113 & 64 \\
\hline & Female & 64 & 36 \\
\hline \multirow{4}{*}{ Age } & $50 \mathrm{~s}$ & 13 & 7 \\
\hline & $60 \mathrm{~s}$ & 57 & 32 \\
\hline & $70 \mathrm{~s}$ & 92 & 52 \\
\hline & $80 \mathrm{~s}$ & 15 & 8 \\
\hline \multirow{3}{*}{ Time taken to the park } & $1-10$ minutes & 122 & 69 \\
\hline & $10-30$ minutes & 37 & 21 \\
\hline & 30-60 minutes & 18 & 10 \\
\hline
\end{tabular}


Table 1. (continued)

\begin{tabular}{|c|c|c|c|c|}
\hline \multicolumn{3}{|c|}{ Classification } & Frequency & Percent $(\%)$ \\
\hline \multirow{3}{*}{ Means of transportation } & \multicolumn{2}{|c|}{ Walking } & 145 & 82 \\
\hline & \multicolumn{2}{|c|}{ Bicycle } & 16 & 9 \\
\hline & \multicolumn{2}{|l|}{ Bus } & 16 & 9 \\
\hline \multirow{3}{*}{ Frequency of park usage } & \multicolumn{2}{|c|}{ Every day } & 115 & 65 \\
\hline & \multicolumn{2}{|c|}{ Three or four times a week } & 48 & 27 \\
\hline & \multicolumn{2}{|c|}{ Once or twice a week } & 14 & 8 \\
\hline \multirow{5}{*}{ Length of stay in the park } & \multicolumn{2}{|c|}{ Less than 1 hour } & 12 & 7 \\
\hline & \multicolumn{2}{|c|}{$1-2$ hours } & 32 & 18 \\
\hline & \multicolumn{2}{|c|}{$2-4$ hours } & 37 & 21 \\
\hline & \multicolumn{2}{|c|}{ More than 4 hours } & 78 & 44 \\
\hline & \multicolumn{2}{|c|}{ All day } & 18 & 10 \\
\hline \multirow{5}{*}{ Time of the day to visit } & \multicolumn{2}{|c|}{ Before 9 o'clock } & 11 & 6 \\
\hline & \multicolumn{2}{|c|}{9 to 12 o'clock } & 23 & 13 \\
\hline & \multicolumn{2}{|c|}{11 to 15 o'clock } & 14 & 8 \\
\hline & \multicolumn{2}{|c|}{15 to 18 o'clock } & 87 & 49 \\
\hline & \multicolumn{2}{|c|}{9 to 18 o'clock } & 42 & 24 \\
\hline \multirow{5}{*}{ Purpose of park usage } & \multicolumn{2}{|c|}{ Spending time with other senior citizens } & 53 & 30 \\
\hline & \multicolumn{2}{|c|}{ Usage of sports facilities } & 46 & 26 \\
\hline & \multicolumn{2}{|c|}{ Usage of trails } & 39 & 22 \\
\hline & \multicolumn{2}{|c|}{ Recreation and rest } & 32 & 18 \\
\hline & Becaus & it can be used freely & 7 & 4 \\
\hline & & Spending time with other senior citizens & 59 & 33 \\
\hline & & Usage of sports facilities & 30 & 17 \\
\hline & $80 \mathrm{~s}$ & Usage of trails & 58 & 33 \\
\hline & & Recreation and rest & 30 & 17 \\
\hline & & Because it can be used freely & 0 & 0 \\
\hline & & Spending time with other senior citizens & 19 & 11 \\
\hline & & Usage of sports facilities & 48 & 27 \\
\hline & $70 \mathrm{~s}$ & Usage of trails & 73 & 41 \\
\hline & & Recreation and rest & 14 & 8 \\
\hline Dumpor of cog by og oroum & & Because it can be used freely & 23 & 13 \\
\hline rupose or usage oy age givups & & Spending time with other senior citizens & 16 & 9 \\
\hline & & Usage of sports facilities & 53 & 30 \\
\hline & $60 \mathrm{~s}$ & Usage of trails & 69 & 39 \\
\hline & & Recreation and rest & 30 & 17 \\
\hline & & Because it can be used freely & 9 & 5 \\
\hline & & Spending time with other senior citizens & 0 & 0 \\
\hline & & Usage of sports facilities & 35 & 20 \\
\hline & $50 \mathrm{~s}$ & Usage of trails & 72 & 40 \\
\hline & & Recreation and rest & 35 & 20 \\
\hline & & Because it can be used free & 35 & 20 \\
\hline
\end{tabular}




\section{What the elders want in the park}

\section{(1) Tapgol Park and Jongmyo Park}

As a result of surveying the facilities the respondents want to have in the parks for the elderly, most of them (35\%) wanted fitness equipment and sports facilities, followed by vegetable garden (29\%), trail (28\%), and recreation and rest (8\%). For multiple responses, there were cultural facilities $(18 \%)$ and management facilities $(2 \%)$.

Meanwhile, as a result of surveying the park programs for the elderly, the respondents showed clear preference for recreational facilities for the elderly such as gateball field, badminton court and table tennis facility (52\%), followed by health and convenience facilities such as health center, pharmacy, snack bar, cafeteria (30\%). This indicates that the elders want facilities to take care of their health and grab a quick bite in the park where they spend a lot of time.

\section{(2) Osolgil Silver Park and Sinteuri Park}

As a result of surveying the facilities the respondents want to have in the parks for the elderly, most of them (33\%) wanted fitness equipment and sports facilities, followed by vegetable garden (31\%), trail (28\%), and recreation and rest (8\%). For multiple responses, there were cultural facilities (14\%) and management facilities (2\%). A high percentage $(31 \%)$ of the elders showed interest in 'vegetable garden', which reflects their familiarity with vegetable gardens and their desire to participate in a productive activity that helps in real life. For the elderly, it might be very difficult to get even the smallest piece of land in the middle of the city and tend a garden. Thus, it is necessary to positively consider implementing facilities for horticultural activities or leisure and welfare of the elderly in a certain part of the park.

As a result of surveying the park programs for the elderly, the respondents showed clear preference for recreational facilities for the elderly such as gateball field, badminton court and table tennis facility (56\%), followed by health and convenience facilities such as health center, pharmacy, snack bar, cafeteria (26\%; Table 2).

\section{(3) Sub-conclusion}

The elderly's geographic activities are reduced by factors such as weakening of physical functions, and thus they have relatively high dependency on life limited to the neighborhood. They have such little mobility that they perceive a distance of 10 minutes from their home as their range of territory (Lee, 2011; Cho and Lee, 2019). Therefore, the fact that various stable and convenient service facilities are located within walking distance is a key factor that affects the elderly's residential environment and improves their satisfaction with life (Cho and Lee, 2019). To improve the quality of elderly life, it is necessary to not only develop welfare policies and programs for the elderly but also improve physical environment and provide support for the elderly's residential environment and neighborhood (Cho and Lee, 2019). Thus far, parks for the elderly or parks renovated for senior citizens have been focused on installing fitness equipment suitable for elderly use or facilities for exercising and leisure, without providing adequate park programs (Chae, 2014). Recently there are growing needs for applying Universal Design (UD) to various social infrastructures in addition to residential space and welfare facili-

Table 2. Preferred facilities by seniors for senior park

\begin{tabular}{|c|c|c|c|}
\hline \multicolumn{2}{|c|}{ Classification } & Frequency & Percent(\%) \\
\hline \multirow{4}{*}{ Facilities they wish to use in a park } & Trails for walking & 50 & 28 \\
\hline & Fitness equipments / sports facilities & 60 & 34 \\
\hline & Vegetable gardens & 53 & 30 \\
\hline & Recreation and rest area & 14 & 8 \\
\hline \multirow{4}{*}{$\begin{array}{l}\text { Facilities they think are necessary in a park } \\
\text { (multiple answers) }\end{array}$} & Health and convenience facility & 50 & 28 \\
\hline & Cultural facility & 28 & 16 \\
\hline & Sports facility & 95 & 54 \\
\hline & Management facility & 4 & 2 \\
\hline
\end{tabular}


ties to improve the quality of elderly life. This indicates that the urban environment must change adequately for the elderly due to the rapid aging. In other words, it is necessary to create an urban environment that is convenient to use from the elderly perspective (Kim, 2004; Cho and Lee, 2019).

\section{Conclusion}

The Korean society is currently showing a decrease in the child population and a rapid increase in the elderly population due to low birth rates and aging, but the current park system fails to reflect the changing population structure. Therefore, with the need for senior-friendly parks for convenient use and improved quality of life from the elderly perspective, we reviewed previous literature and analyzed the elderly's usage behavior and preference in parks crowded with the elderly and parks renovated into senior-friendly parks. The results of this study are as follows.

First, the elders mostly gathered in certain parks or nearby areas in the urban center like Tapgol Park and Jongmyo Park. There is usually an accessible subway station near the area crowded with the elderly. Amenities such as reasonably priced shops and restaurants as well as a traditional market used by the elderly are located around the park. The elders usually gathered around buffer zones or green spaces set up to protect cultural heritages.

Second, as a result of examining the elderly's park usage and current state of Osolgil Silver Park and Sinteuri Park in Yangcheon-gu, Seoul, the most distinct feature was that, while places generally crowded by the elderly are formed based on certain conditions (such as urban center, park, close to the subway station, close to the traditional market, green area), these parks were visited by many elders to socialize regardless of these conditions. This was mainly due to the following reasons: (1) these parks were established based on the theme 'seniors only' or 'senior-friendly' and thus the elders could visit without feeling uncomfortable with other generations; (2) the parks were equipped with the internal environment that encouraged the elderly's positive activities by associating the users with facilities that considered their behavior; (3) efforts were made by the gu office (in charge of park management) to maintain and manage the spaces in the park where the elders could gather together and socialize; and (4) the concept of 'social mix' was considered for the harmony of multiple generations to adequately form the spaces for the community as well as spaces exclusively for the elderly.

Third, the locational conditions for the senior-friendly parks reflecting the elderly dispositions and actual demand were: (1) accessible to the elderly, (2) located in the urban center with energy of life, (3) can be used for free, (4) a wide green area, (5) reasonably priced amenities nearby, (6) facilities naturally shared among different generations, (7) spaces to hold various events for the elderly to feel a sense of belonging and interest, and (8) windbreaks in rest areas to block the cold winds in the winter.

Fourth, the survey results showed that the elders walked to the park every week (at least once a week to every day), and $54 \%$ of them stayed in the park for more that 4 hours. By age, most of the elders from their 60 s to 80 s visited the park to exercise and take a walk (around the track). Moreover, older groups tended to visit the park more to meet other elders around their age, that is, for socializing purposes. As such, the parks were used as a meeting place for socializing activities and various forms of interactions with neighbors.

Fifth, most of the elders wanted fitness equipment and sports facilities like a trail, track, and gateball field to be established in parks for the elderly. Many of them also wanted a vegetable garden for productive activities to help the sentiment and real life of the elderly and an indoor rest area to avoid the wind in cold weather. However, since the parks examined in this study already had windbreaks installed for the pavilions, the respondents were generally satisfied with them.

Renovating or creating parks for the elderly is not a matter of extensive maintenance with massive resources and finances. Rather, it is necessary to allocate a certain amount of space for the elderly to feel a sense of unity as members of the community, thereby connecting this space to a new community space of the city. The results of this study are anticipated to contribute to planning and promoting parks for the elderly in preparation for the aging society. 


\section{References}

Chae, S.D. 2014. Basic research for planning and activation of senior park. Master's thesis, Korea University, Seoul, Korea.

Cho, H and S. Lee. 2019. A study on the inducement distance of senior-friendly park and evaluation of green service area: Focused on the pedestrian aspect. J. Korean Inst. Landsc. Archit. 47(1):1-9. https://doi.org/10.9715/KIL A.2019.47.1.001

Ju, Y.T. 2010. A study on ways of improving the quality of leisure life for elderly: Focusing on elderly around Jongmyo and Tapgol Park area. Master's thesis, University of Seoul, Seoul, Korea.

Kang, E.S. 2004. A study on the development of leisure program for senior theme park: Focused on the conceptual design of senior leisure town. Master's thesis, Myungji University, Seoul, Korea.

Kang, S.J. and E.A. Park. 2010. Planning for the senior-friendly park in considerations of senior usage of park. (Policy Brief 2010-23). Suwon, Korea: Gyeonggi Research Institute.

Kim, M.I. 2012. A study on senior citizens' park usage patterns and revitalizing plans for their leisure culture: Focusing on senior citizens' use of the Hwangseong Park, Gyeongju City. Master's thesis, Kyungpook National University, Daegu, Korea.

Kim, K. 2004. A study on the change of the living con- dition and the role of the universal design in an aged society. J. Korean Soc. Des. Sci. 17(2):231-240.

Kim, S.J. 2009. A study on the cultural technology for the collective culture of the elderly: Focused on the daily life of the elderly at Jongmyo Park. Korean J. Soc. Welf. Stud. 40(3):349-375.

Lee, D.Y. 2012. A study on the space-design of theme park by the analysis of New Silver Generation. Master's thesis, Andong National University, Andong, Korea.

Lee, H.S. 2011. Perception of proximity to and utilization of neighborhood services and facilities for senior citizens: Focused on the Seongnam area. J. Urban Des. Inst. Korea 12(4):63-74.

Lee, K.S. 2009. A study on the activation of elderly culture in Jongno, Seoul: Focusing on senior users of Jong-myo and Top-gol Park. Master's thesis, University of Seoul, Seoul, Korea.

Lee, S.Y. and H.J. Kim. 2003. Characteristics of elderly people's urban park usage: Focused on Tapgol-Park. Proceedings of Spring Conference for the Architectural Institute of Korea. 23(1):143-146.

Oh, C.H. 2018, April 18. It is necessary to turn city parks into senior-friendly parks. Lafent Landscape News. Retrieved from https://www.lafent.com/inews/news_vie w.html?news_id=121660

Song, H.J. and G.M. Nam. 2008. Utilization status of the aged park and its activation plan: Focused on Cheongju ChungAng Park. Korean J. Gerontol. Soc. Welf. 39:217-247. 